\title{
Effect of troposphere slant delays on regional double difference GPS processing
}

\author{
Maaria Nordman ${ }^{1}$, Reima Eresmaa ${ }^{2}$, Johannes Boehm ${ }^{3}$, Markku Poutanen ${ }^{1}$, \\ Hannu Koivula $^{1}$, and Heikki Järvinen ${ }^{2}$ \\ ${ }^{1}$ Finnish Geodetic Institute, P.O. Box 15, 02431 Masala, Finland \\ ${ }^{2}$ Finnish Meteorological Institute, P.O. Box 503, 00101 Helsinki, Finland \\ ${ }^{3}$ Institute of Geodesy and Geophysics, Vienna University of Technology, Gusshausstrasse 27-29, 1040 Vienna, Austria
}

(Received July 7, 2008; Revised March 10, 2009; Accepted March 11, 2009; Online published August 31, 2009)

\begin{abstract}
The demand for geodetic time series that are accurate and stable is increasing. One factor limiting their accuracy is troposphere refraction, which is hard to model and compute with sufficient resolution, both in time and space. We have studied the effect of numerical weather model (NWM)-derived troposphere slant delays and the most commonly used mapping functions, Niell and Vienna, on Global Positioning System (GPS) processing. Six months of data were calculated for a regional Finnish network, FinnRef, which consists of 13 stations, using Bernese v. 5.0 in double difference mode. The results showed that when site-specific troposphere zenith delays or gradients are not estimated, the use of NWM-based troposphere delays improved the repeatabilities of all three components of station positions (north, east and up) statistically significantly and up to 60\%. The more realistic troposphere model also reduces the baseline length dependence of the solution. When site-specific troposphere delays and the horizontal gradients were estimated, there was no statistically significant improvement between the different solutions.
\end{abstract}

Key words: Troposphere slant delays, geodetic time series, GPS processing, double difference mode.

\section{Introduction}

Accurate and stable time series of geodetic parameters are a crucial part of reference frame realisation and maintenance, geodynamic studies and other geodetic and geophysical applications. There are several radio-frequencybased geodetic techniques, such as GNSS (Global Navigation Satellite System, including Global Positioning System (GPS), GLONASS and Galileo), VLBI (Very Long Baseline Interferometry) and satellite altimetry, which provide time series that are used for numerous purposes. The accuracy and stability of these time series are restricted by several factors, including ionospheric delay, tropospheric delay and multipath interference. In this paper we concentrate on the effect of the tropospheric delay on coordinate time series.

Signal delay varies due to changes in troposphere refractivity. Refractivity changes can be local and rapid and are, therefore, not easy to compute with an adequate spatial and temporal resolution. The effect has traditionally been calculated using a mapping function approach, where the troposphere slant delay is related to the troposphere zenith delay with a mapping function. The zenith delay is computed from ground-based observations or derived from a numerical weather model. The mapping function (mf) is typically

Copyright (c) The Society of Geomagnetism and Earth, Planetary and Space Sciences (SGEPSS); The Seismological Society of Japan; The Volcanological Society of Japan; The Geodetic Society of Japan; The Japanese Society for Planetary Sciences; TERRAPUB a continued fraction form, e.g.

$$
\mathrm{mf}=\frac{1+\frac{a}{1+\frac{b}{1+c}}}{\sin \left(e_{\mathrm{a}}\right)+\frac{a}{\sin \left(e_{\mathrm{a}}\right)+\frac{b}{\sin \left(e_{\mathrm{a}}\right)+c}}},
$$

where $e_{\mathrm{a}}$ is the elevation angle. Coefficients $a, b$ and $c$ can be derived, for example, from weather models, as discussed later.

The commonly used Niell Mapping Function (NMF; Niell, 1996) is based on climatological temperature and relative humidity profiles and is independent of the surface meteorology. Next-generation mapping functions are based on numerical weather models (NWM). The isobaric mapping function (IMF) uses the intermediate parameters of NWM (Niell, 2001), and the parameters of the Vienna mapping function (VMF and VMF1) are based on ray tracing through the atmosphere (Boehm and Schuh, 2004; Boehm et al., 2006a). The global mapping function (GMF) was developed to combine the accuracy of the VMF1 and the coverage of the NMF (Boehm et al., 2006b). Tesmer et al. (2007) compare these mapping functions for the VLBI. There are also studies dealing with the determination of the mapping function parameters from numerical weather models valid for a limited area, such as the HIRLAM (High Resolution Limited Area Model) (Stoyanov et al., 2004; Eresmaa et al., 2008).

Water vapour estimates from the GPS and VLBI can be also used as weather model inputs (Elgered et al., 2005; 
Troller et al., 2006). There are several studies on troposphere delay validation using water vapour radiometers, GPS and VLBI (Niell et al., 2001; Snajdrova et al., 2006 and references therein; Krügel et al., 2007).

The double difference solution is one of the most common approaches used to determine station coordinates in a GPS network. In the study reported here, we used the double difference solution of Bernese v. 5.0 (Dach et al., 2007) to compute vectors between GPS stations. One station was kept fixed, and the coordinates of the other station were estimated using different troposphere parameter estimation options. Six months of data were used to compare the performance of the widely used mapping-functionbased approach with the direct-ray-tracing approach for tropospheric correction. We relied on the Finnish permanent GPS network, which consists of 13 stations. Preliminary results on the behaviour of the up component can be found in Nordman et al. (2007). In this study, we compare 15 different approaches and also present the results for the horizontal components.

\section{Analysis}

The challenge in determining the parameters of a mapping function is to describe the troposphere by just a few coefficients. Therefore, in the case of a passing synoptic disturbance, for example, the azimuthal anisotropy in the delay is not taken into account. We have used two approaches for the NWM utilisation. First, a zenith delay is derived from the NWM, and additional troposphere parameters are estimated in the processing. In this approach azimuthal asymmetry can only be estimated using gradient estimation. Secondly, we have introduced a method to subtract NWM-based troposphere slant delays at the observation level from GPS RINEX (Receiver INdependent EXchange Format) files. These NWM-based troposphere slant delays are both azimuth- and elevation-angle dependent (Nordman et al., 2007). Corrections at the observation level can also be applied for other error sources, and the method is not dependent on processing software. The removal of errors at the observation level decreases the number of unknowns in the processing and can thus make the computation faster and more robust. Tregoning and van Dam (2005) used a similar approach for the correction of crustal loading. Correction at the observation level for the ray-traced slant delays has also been studied for precise point positioning processing (Hobiger et al., 2008).

In GPS processing, the troposphere delay is usually handled in two parts, hydrostatic and wet. The hydrostatic part, which is about $90 \%$ of the whole delay, is taken from an $a$ priori model, and the wet part is estimated in the processing. Two cases are examined here. The first case simulated standard commercial processing software with no sophisticated troposphere estimation routines; in this simulation, no additional parameter estimation was used in the computation. This approach can be used, for example, for realtime navigation or for ordinary surveying applications. In the second case, we studied the performance of different advanced troposphere estimates and mapping functions. It is known that numerical weather models are imperfect and that some residual troposphere estimation is necessary (Ho- biger et al., 2008). We used the wet Niell mapping function for consistency with our standard processing. The residual parameter estimation probably also accounts for other angle-dependent errors, such as multipath or higher-order ionosphere terms. This can be either an advantage or disadvantage. If the errors terms are estimated and compensated for, the solution becomes more stable. On the other hand, all of the terms are summed up, and we cannot tell which part is which; as such, the error sources cannot be modelled separately. The parameter estimation can also compensate for real time series variation, for example, due to atmospheric or hydrological loading, which may result in less realistic time series.

\section{Data}

\subsection{Numerical weather models}

This study applied two NWMs. First, we used an operational implementation of HIRLAM (Undén et al., 2002), which is run at the Finnish Meteorological Institute. In the second approach we used the output of the ERA-40 reanalysis (Simmons and Gibson, 2000) of the European Centre for Medium-range Weather Forecasts (ECMWF).

The HIRLAM model was taken with a 9-km horizontal grid spacing at 40 model levels in the vertical. In the case of the ERA-40, the grid spacing was $125 \mathrm{~km}$ at 60 model levels. The lateral boundary conditions for the HIRLAM model were extracted from the operational forecasts of the ECMWF global model.

\subsection{HIRLAM slant delays by ray tracing}

Tropospheric slant delay is obtained through numerical integration of the refractivity along the path of signal. The slant delay is a function of the elevation and the azimuth of the satellite and of the receiver coordinates and time. The determination of the path of the signal relies on the layerwise approximation of a straight geometric line across the HIRLAM grid. The refractive bending is corrected iteratively using an explicit correction that is based on the distribution of refractivity along the signal path. The Saastamoinen model is used for the slant delay derivation above the model top level. For more details on the algorithm, see Eresmaa and Järvinen (2006).

For each GPS observation epoch, the numerical forecast with the shortest possible lead time is used. Since HIRLAM is run with a 6-h cycling (i.e. analyses are produced every $6 \mathrm{~h}$ ), and the model output is recorded for every forecast hour, the slant delays are derived from forecasts with lead times of between 0 and $5 \mathrm{~h}$. In principle, updating of the model atmosphere induces a discontinuity between the previous 6-h forecast and the new initial field ( 0 -h forecast). This discontinuity appears as an analysis increment, and its significance can be assessed by statistical methods. In this study, such methods have been applied to 1 month of HIRLAM forecasts. It turns out that, in the case of integrated water vapour, the root-mean-square analysis increment is less than half of the root-mean-square difference between consecutive forecasts of lead times $L$ and $L+1$ hours. It is thus concluded that discontinuities between any two forecasts that are valid at successive hours, even if they originate from the same analysis, prevail over the discontinuities that are attributed to the updating of the model at- 
mosphere.

The total slant delays were derived for every satellite at every epoch by means of linear interpolation. These delays were converted to GPS L1 and L2 signal carrier wavelengths and then subtracted consecutively from the phase measurements in the observation RINEX files. The corresponding code data were corrected directly with the slant delay.

\subsection{VMF1 and NWM zenith delays}

We used the Vienna Mapping Function (VMF1; Boehm et al., 2006a) for our comparisons. Since the VMF1 is not implemented in Bernese, we computed slant delays using hydrostatic and wet zenith delays as well as mapping function parameters derived from ECMWF every $6 \mathrm{~h}$. We calculated total slant delays using the VMF1 and manipulated the RINEX files in the same way as we did the HIRLAM slant delays.

In order to compare the performance of the NWM and the differences in the mapping functions, we derived zenith delays from both HIRLAM and ECMWF and introduced them as known in the processing. The total zenith delay is computed as the sum of the wet and hydrostatic part. Since the site-specific troposphere zenith delays are estimated assuming that the hydrostatic part of the troposphere is known and the wet part is unknown, we derived both total and hydrostatic zenith delays. The total zenith delays were used when no additional parameters were estimated, and the hydrostatic zenith delays were used when site-specific troposphere zenith delays were estimated. The resolution of the ECMWF data used in this study is sparse, about $125 \mathrm{~km}$. It is, therefore, unclear if it provides much additional information, especially in the case of our shorter baselines.

\subsection{GPS data}

We used 6 months (184 days) of data from the Finnish permanent GPS network, FinnRef. The network consists of 13 stations between the latitudes $60^{\circ} \mathrm{N}$ and $70^{\circ} \mathrm{N}$, with calculated vector lengths varying from 110 to $1100 \mathrm{~km}$ (Fig. 1). The time period 1 May-31 October 2006 was chosen in order to exclude observations recorded while the antenna may have been covered by snow, because snow can distort solutions markedly (Poutanen et al., 2005).

\section{GPS Processing}

We used the GPS processing software Bernese v. 5.0 (Dach et al., 2007) to calculate daily station coordinates with the ionosphere-free L3 combination in double difference mode. We formed a total of 12 vectors radially from METS (Fig. 1). The coordinates of METS were kept fixed to ITRF2000 (International Terrestrial Reference Frame; Boucher et al., 2004) (epoch 2005.7). The elevation cut-off angle was $5^{\circ}$, and an elevation-dependent weighting using $\cos ^{2}(z)$ was adopted. Station-specific ocean load tables were also employed (Bos and Scherneck, http://www.oso.chalmers.se/ loading/). All of the time series were calculated in the same way, except for the troposphere handling. There were 15 different processing options, summarised in Table 1.

In GPS processing, the total troposphere correction is the sum of two parts: the hydrostatic part, which is taken from an a priori model, and a wet part, which is estimated in the

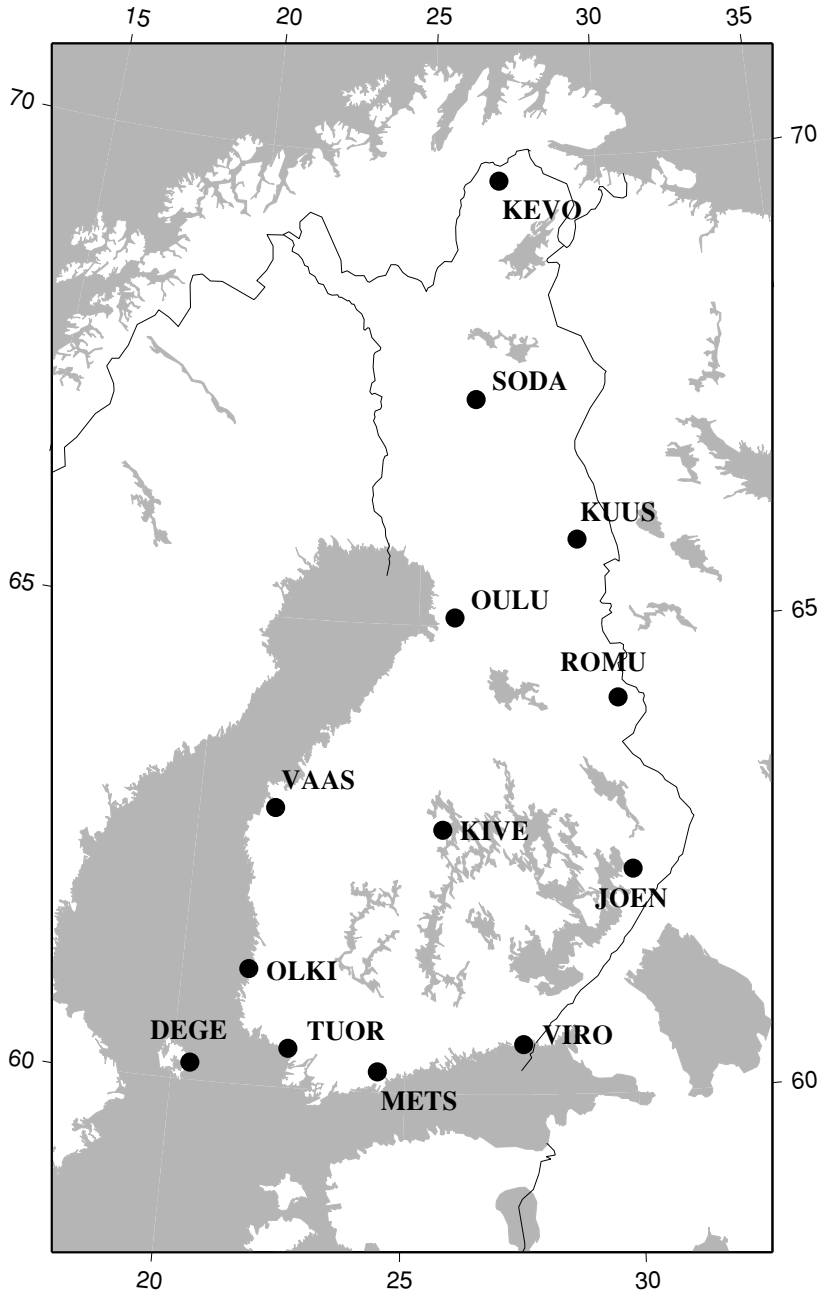

Fig. 1. The FinnRef network of permanent GPS stations.

processing. In our computations, we use this approach in three processing schemes. First, we used the Niell mapping function, i.e. Saastamoinen zenith delays and Niell mapping function as provided by the Bernese software without any modifications (SN). Secondly, we derived (hydrostatic or total) zenith delays from an NWM, subsequently using these as an input together with the Niell mapping function ( $\mathrm{HN}$ and $\mathrm{EN})$. Another way of correcting the troposphere is to derive the total slant delays. We derived these total slant delays from an NWM, removing them directly from the observations (modified RINEX files) and processing data without any troposphere estimation (HS). This processing scheme is explained in more detail in Nordman et al. (2007). The EV solution was implemented in the same way as the HS, i.e. with RINEX manipulation.

There were also three options in the troposphere estimation in Bernese, which were all taken into account. The simplest one used no additional parameters (00). The second one used site-specific troposphere zenith delay estimation (10) and the most sophisticated one used both site-specific troposphere zenith delay estimation and horizontal gradient estimation (11). The site-specific troposphere zenith delays are station- and time-dependent corrections to the a priori model, from now on referred to as site-specific parameters. We used the wet NMF for the parameter estimation, with 
Table 1. Different troposphere handling schemes. The code for each scheme is an abbreviation. The first letter signifies the troposphere model ( $\mathrm{S}=$ Saastamoinen, $\mathrm{H}=$ HIRLAM and $\mathrm{E}=$ ECMWF; Troposphere model column), and the second letter indicates the mapping function ( $\mathrm{N}=\mathrm{NMF}, \mathrm{S}=$ slant delay and $\mathrm{V}=\mathrm{VMF} 1$; MF-column). The last two numbers indicate whether site-specific parameters and gradients were used or not $(0=$ not used, $1=$ used $)$.

\begin{tabular}{ccccc}
\hline Abbreviation & Troposphere model & MF & Site-specific & Gradients \\
\hline SN00 & Saastamoinen & Niell & no & no \\
SN10 & Saastamoinen & Niell & yes & no \\
SN11 & Saastamoinen & Niell & yes & yes \\
HN00 & HIRLAM & Niell & no & no \\
HN10 & HIRLAM_dry & Niell & yes & no \\
HN11 & HIRLAM_dry & Niell & yes & yes \\
EN00 & ECMWF & Niell & no & no \\
EN10 & ECMWF_dry & Niell & yes & no \\
EN11 & ECMWF_dry & Niell & yes & yes \\
HS00 & HIRLAM & Slant & no & no \\
HS10 & HIRLAM & Slant & yes & no \\
HS11 & HIRLAM & Slant & yes & yes \\
EV00 & ECMWF & Vienna & no & no \\
EV10 & ECMWF & Vienna & yes & no \\
EV11 & ECMWF & Vienna & yes & yes \\
\hline
\end{tabular}

a parameter spacing of $2 \mathrm{~h}$. Horizontal gradient estimation is a common way of coping with the azimuthal asymmetry of the local troposphere. The gradients are estimated once every $24 \mathrm{~h}$.

\subsection{RINEX manipulation test}

We tested our RINEX manipulation scheme using the Saastamoinen model. Saastamoinen is a troposphere refractivity model based on the laws associated with ideal gas (Saastamoinen, 1973). We calculated slant delays using

$\Delta \rho=\frac{0.002277}{\cos z}\left[p+\left(\frac{1255}{T}+0.05\right) e-B \tan ^{2} z\right]+\delta R$,

which is the formula (11.11) in the Bernese manual (Dach et al., 2007). $\Delta \rho$ is the troposphere slant delay; $z$ is the satellite's zenith distance; $p, e$ and $T$ atmospheric pressure, partial water vapour pressure and temperature, respectively. $B$ and $\delta R$ are correction terms of which the former is dependent on the station height and the latter is not yet implemented in Bernese. We then corrected the RINEX files with the computed slant delays.

We calculated two 9-day time series using the same data. The first time series was produced using the manipulated RINEX and the second with original, un-manipulated files together with the Saastamoinen model within Bernese-in both cases without any site-specific parameters. The result for the up component of all the stations can be seen in Fig. 2. The crosses were calculated using the Saastamoinen model enabled in Bernese, and the circles were calculated with the manipulated files. Typically, the up component is the one to show the greatest variance and discrepancies in the time series. One of the reasons for this is that the troposphere zenith delays are highly correlated with the up component due to the observation geometry.

As Fig. 2 shows, the differences between the up time series are small; for the horizontal components, the differences are even smaller. The standard deviations for

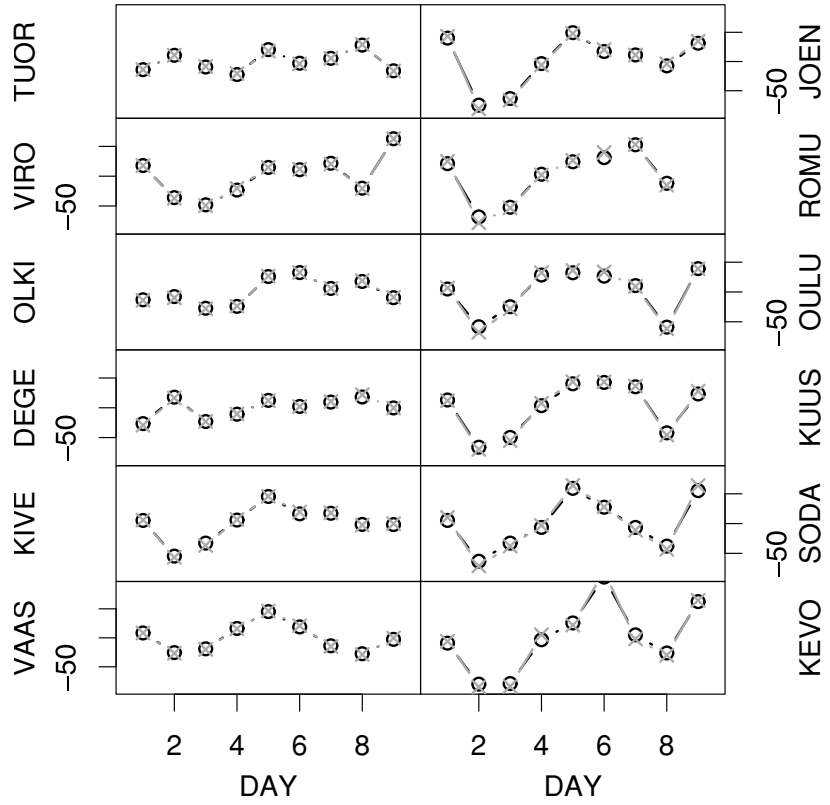

Fig. 2. The up component of 12 stations for 9 days. The crosses are the data computed with Saastamoinen within Bernese, and the circles are the manipulated data solutions. The scale is in millimetres.

the stations are $1-17 \mathrm{~mm}, 2-7 \mathrm{~mm}$ and $17-64 \mathrm{~mm}$ in the north, east and up component, respectively, for the unmanipulated files, and 1-15 mm, 2-8 mm and 17-60 mm for the same components using the manipulated files. The differences are not statistically significant even at an $80 \%$ confidence level. Another measure for the goodness of the solution is the root-mean-square (RMS) of the residuals. This test shows that the manipulated files have a twoto threefold larger RMS than the un-manipulated files, although the same Saastamoinen model is used in both and no site-specific parameters or gradients are estimated in either. The RMS also seems to be dependent on the baseline length when using the manipulated data, but the reason for this is unknown. Since the standard deviations of the manipulated and un-manipulated data are alike, we choose to use the standard deviation (repeatability) of the time series for the comparisons in the next section.

\section{Results}

The GPS processing produced 15 different time series for all of the stations and for all three components. Five single values with the largest difference to the mean were removed as outliers, and the standard deviation for each processing scheme, station and component was then calculated. The standard deviation represents the repeatability of the solution. A one-sided $F$-test (e.g. Brandt, 1999) with $99 \%$ confidence level was used to compare the statistical significance of the differences between processing schemes.

An example of the time series for the OULU station can be seen in Fig. 3. Three processing schemes that produced the best results (i.e. the lowest standard deviations) were chosen, namely SN11, HS10 and EV11. All of the time series behaved quite similarly. The HS10 solution (grey line) of OULU scatters slightly more than the SN11 and EV11 solutions, as is the case for all the stations. This re- 


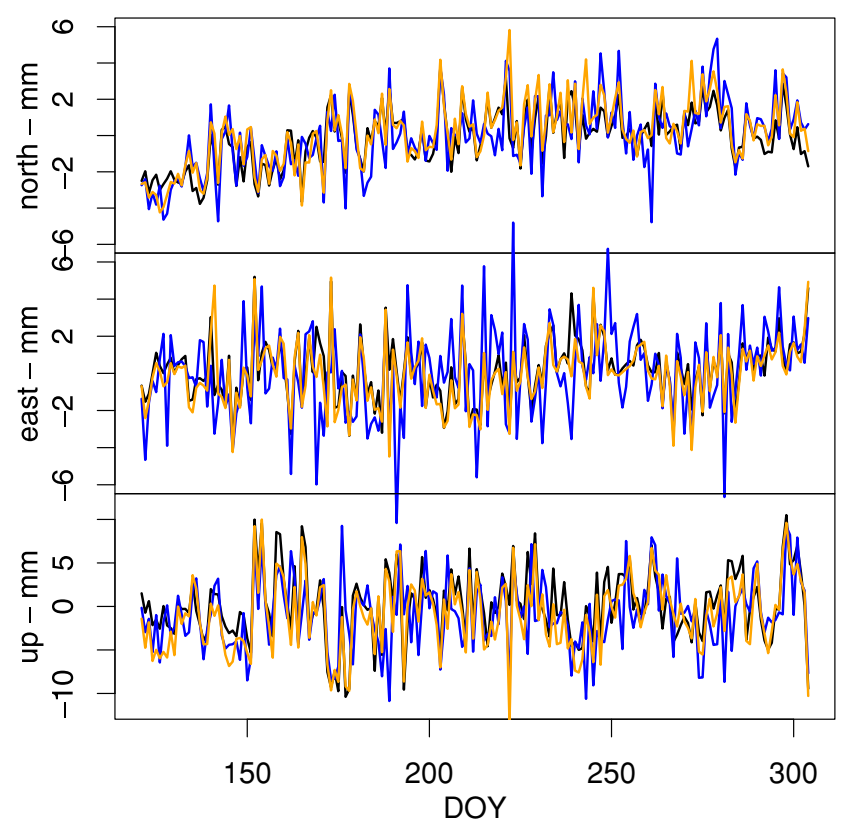

Fig. 3. Example from Oulu of the time series of all three components. The solid black line is SN11, the grey line (blue) HS10 and the dotted black line (orange) EV11. Note that the range for the horizontal component is $12 \mathrm{~mm}$ and for the vertical component, $24 \mathrm{~mm}$.

sult indicates that the gradients estimated during the GPS processing perform better than gradient estimation from the HIRLAM model. The HS10 of OULU was slightly more scattered in the east component than the others, which may be explained by the position of the OULU station near the coast of the Baltic Sea. The coast extends in a north-south direction, which leads to a permanent azimuthal inhomogeneity in the troposphere-the land-sea difference. Only if the gradients are estimated is the east-west inhomogeneity for OULU considered; otherwise they are not, and the east component time series is more scattered. However, none of the other coastal GPS stations had the same behaviour. The other time series for OULU have the same characteristics; only the ranges vary, depending on the solution. The SNO0 has a range of $60 \mathrm{~mm}$ in the north component, whereas the HSO0 has a range of $20 \mathrm{~mm}$.

The standard deviations of three time series for all the stations are depicted in Fig. 4. The SN00 solution (circles) has the greatest scatter in all three components. When NWMbased troposphere delays are used, the scatter reduces remarkably (HSO0, triangles), and the baseline length dependence of the standard deviation is also reduced. The SN11 (plus signs) shows the behaviour of a less-scattered time series. As Table 2(b, c) shows, all of the time series using additional parameter estimation are in the same order of magnitude. The scatter of the vector component is dependent on the azimuth of the baseline. Due to the geometry of our GPS network, the vectors of this study are mostly oriented in the north-south direction, which explains the length dependence of the north component.

Table 2(a) presents the standard deviations for all of the stations and all of the components for the 00-processing schemes, i.e. schemes with no additional parameter estimation. The last line shows the mean value of each column.

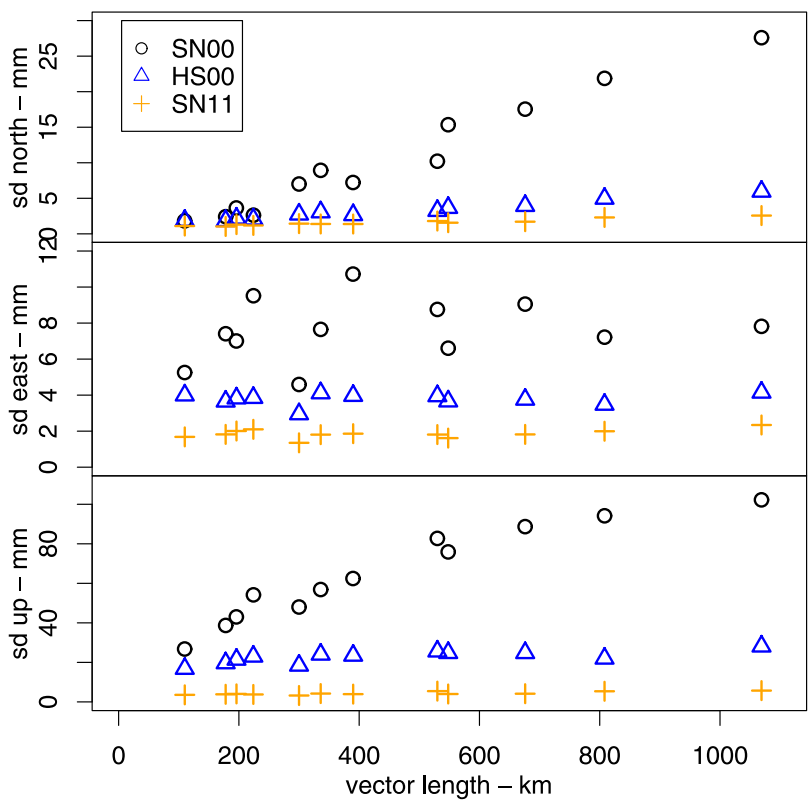

Fig. 4. The standard deviation of all the stations and processing schemes SN00, HS00 and SN11 for all three components, north, east and up (in $\mathrm{mm})$. Note that the scale for each component is different.

The HSO0 scheme gives the lowest standard deviation in most cases, as expected, because it is the scheme that both uses the most accurate troposphere model and accounts for the azimuthal asymmetry. It can be also seen that all of the schemes are affected by vector length, although SN00 is the most extreme example. All of the reductions from SN00 to any other processing scheme are statistically significant, except for the north component of TUOR and VIRO.

Table 2(b) presents the results for 10-processing schemes, as processed with site-specific parameter estimation. No specific conclusions can be drawn; for the north component, SN10 gives the lowest standard deviation, but for the east component HS10 is better. One reason for discrepancy is that in Finland the weather fronts often propagate in an easterly or northeasterly direction. In this case, the solution with gradients, HS10, gives the best results. For the up component, EV10 is the best, but HS10 is also quite good. It is worth noting that the differences between different schemes are small—tenths of millimetres in most cases - and thus not statistically significant.

Table 2(c) presents the standard deviations for the 11processing schemes, i.e. with both site-specific parameters and gradient estimation. Standard Bernese processing using both the site-specific parameter and gradient estimation (SN11) yields the best results for all three components. As for the 10-processing schemes in Table 2(b), none of the differences are statistically significant. The HS11 does not have a single low value. This might be due to the fact that azimuthal differences are already included in the slant delay derivation and, therefore, the gradient estimation does not increase the accuracy.

Table 3 is a summary of Table 2 and presents a comparison of standard deviation reductions for all the stations. The mean of the standard deviations for all 12 stations and 15 processing schemes has been calculated, and the reduc- 
Table 2. (a) Standard deviations in millimetres for the 00-processing schemes. The abbreviations are explained in Table 1. The lowest (best) standard deviation values are in bold and italics for each station and component, respectively. The last line is the mean value of all the stations. (b) Same as Table 2(a), results for 10-schemes. (c) Same as Table 2(a), results for 11-schemes.

(a)

\begin{tabular}{|c|c|c|c|c|c|c|c|c|c|c|c|c|c|c|c|c|}
\hline Station & $\begin{array}{c}\text { Length } \\
(\mathrm{km})\end{array}$ & SN00 & \multicolumn{3}{|c|}{ North $(\mathrm{mm})$} & EV00 & \multicolumn{4}{|c|}{ East $(\mathrm{mm})$} & EV00 & SN00 & \multicolumn{3}{|c|}{$\mathrm{Up}(\mathrm{mm})$} & EV00 \\
\hline TUOR & 110 & 1.8 & 1.9 & 1.9 & 1.9 & 2.0 & 5.2 & 4.0 & 4.1 & 4.0 & 4.2 & 26.8 & 17.1 & 20.4 & 16.8 & 21.0 \\
\hline VIRO & 178 & 2.4 & 2.1 & 2.1 & 1.8 & 2.1 & 7.4 & 4.0 & 3.8 & 3.7 & 3.9 & 38.7 & 20.6 & 22.6 & 19.7 & 22.3 \\
\hline OLKI & 196 & 3.7 & 2.3 & 2.3 & 2.2 & 2.2 & 7.0 & 4.2 & 4.7 & 3.8 & 4.8 & 43.0 & 22.8 & 36.7 & 21.5 & 35.1 \\
\hline DEGE & 224 & 2.6 & 2.0 & 2.1 & 2.0 & 2.0 & 9.5 & 4.2 & 4.4 & 3.9 & 4.5 & 54.2 & 23.5 & 28.6 & 23.0 & 27.4 \\
\hline KIVE & 300 & 7.0 & 2.8 & 2.8 & 2.7 & 3.0 & 4.6 & 3.0 & 3.0 & 2.9 & 3.2 & 48.0 & 19.1 & 24.1 & 18.4 & 24.5 \\
\hline VAAS & 336 & 8.9 & 3.3 & 3.6 & 3.1 & 3.7 & 7.6 & 4.7 & 5.4 & 4.1 & 5.4 & 56.9 & 23.8 & 31.5 & 24.0 & 31.9 \\
\hline JOEN & 390 & 7.2 & 2.9 & 2.8 & 2.7 & 2.8 & 10.7 & 4.4 & 4.0 & 4.0 & 4.0 & 62.5 & 23.8 & 26.4 & 23.5 & 26.2 \\
\hline ROMU & 530 & 10.2 & 4.1 & 3.6 & 3.3 & 3.6 & 8.8 & 4.1 & 3.6 & 4.0 & 3.6 & 82.7 & 26.2 & 28.0 & 25.6 & 27.0 \\
\hline OULU & 548 & 15.3 & 4.3 & 4.4 & 3.7 & 4.5 & 6.6 & 3.8 & 3.9 & 3.7 & 3.7 & 76.0 & 25.2 & 37.9 & 24.8 & 37.5 \\
\hline KUUS & 676 & 17.6 & 4.7 & 4.8 & 4.0 & 4.7 & 9.1 & 4.1 & 4.0 & 3.8 & 3.9 & 88.7 & 24.3 & 25.5 & 24.8 & 25.1 \\
\hline SODA & 808 & 21.9 & 5.5 & 5.4 & 5.0 & 5.6 & 7.2 & 3.8 & 4.0 & 3.5 & 3.8 & 94.2 & 23.3 & 26.6 & 22.0 & 25.2 \\
\hline KEVO & 1069 & 27.6 & 6.5 & 6.1 & 6.0 & 6.4 & 7.8 & 4.5 & 4.6 & 4.1 & 4.4 & 102.3 & 28.3 & 27.1 & 28.1 & 26.1 \\
\hline Mean & & 10.5 & 3.5 & 3.5 & 3.2 & 3.6 & 7.6 & 4.1 & 4.1 & 3.8 & 4.1 & 64.5 & 23.2 & 27.9 & 22.7 & 27.4 \\
\hline
\end{tabular}

(b)

\begin{tabular}{|c|c|c|c|c|c|c|c|c|c|c|c|c|c|c|c|c|}
\hline Station & $\begin{array}{c}\text { Length } \\
(\mathrm{km})\end{array}$ & \multicolumn{5}{|c|}{ North (mm) } & SN10 & HN10 & $\begin{array}{l}\text { EN10 } \\
\text { ast (m }\end{array}$ & HS10 & EV10 & SN10 & \multicolumn{3}{|c|}{$\mathrm{Up}(\mathrm{mm})$} & EV10 \\
\hline TUOR & 110 & 1.6 & 1.6 & 1.6 & 1.6 & 1.7 & 2.2 & 2.3 & 2.3 & 2.2 & 2.2 & 3.8 & 3.8 & 3.9 & 4.2 & 3.9 \\
\hline VIRO & 178 & 1.8 & 1.9 & 1.8 & 1.6 & 1.9 & 2.9 & 3.0 & 3.0 & 2.7 & 3.0 & 4.2 & 4.7 & 4.7 & 4.5 & 4.1 \\
\hline OLKI & 196 & 1.8 & 2.0 & 2.0 & 1.8 & 1.8 & 2.9 & 3.0 & 3.0 & 2.4 & 2.7 & 4.4 & 4.9 & 4.9 & 4.5 & 4.1 \\
\hline DEGE & 224 & 1.9 & 1.9 & 1.9 & 1.9 & 2.0 & 3.2 & 3.3 & 3.4 & 2.7 & 3.2 & 4.9 & 6.1 & 5.8 & 4.4 & 4.5 \\
\hline KIVE & 300 & 1.6 & 2.3 & 2.2 & 1.9 & 1.6 & 2.1 & 2.2 & 2.2 & 2.0 & 2.4 & 3.2 & 3.7 & 3.7 & 3.3 & 3.4 \\
\hline VAAS & 336 & 1.9 & 2.5 & 2.4 & 2.0 & 1.9 & 2.6 & 2.7 & 2.7 & 2.4 & 2.6 & 5.0 & 5.4 & 5.5 & 4.3 & 5.0 \\
\hline JOEN & 390 & 2.0 & 2.4 & 2.4 & 2.0 & 2.1 & 2.9 & 3.1 & 3.1 & 2.8 & 3.0 & 4.7 & 6.6 & 6.6 & 4.8 & 4.6 \\
\hline ROMU & 530 & 1.9 & 2.8 & 2.7 & 2.0 & 2.1 & 2.7 & 2.7 & 2.8 & 3.0 & 2.7 & 5.6 & 7.9 & 7.9 & 5.6 & 5.3 \\
\hline OULU & 548 & 1.9 & 3.1 & 3.0 & 2.0 & 2.0 & 2.7 & 2.7 & 2.7 & 2.5 & 2.8 & 4.3 & 6.9 & 6.9 & 4.1 & 3.8 \\
\hline KUUS & 676 & 2.0 & 3.7 & 3.6 & 2.1 & 2.2 & 2.9 & 2.9 & 3.0 & 2.6 & 3.0 & 5.0 & 7.7 & 7.7 & 4.5 & 4.5 \\
\hline SODA & 808 & 2.5 & 4.7 & 4.6 & 2.8 & 2.7 & 2.7 & 2.9 & 2.9 & 2.5 & 2.8 & 5.6 & 9.1 & 9.1 & 5.4 & 5.0 \\
\hline KEVO & 1069 & 2.9 & 5.4 & 5.3 & 3.1 & 3.3 & 3.1 & 3.2 & 3.2 & 3.1 & 3.3 & 5.8 & 9.5 & 9.4 & 5.7 & 5.7 \\
\hline Mean & & 2.0 & 2.9 & 2.8 & 2.0 & 2.1 & 2.7 & 2.8 & 2.9 & 2.6 & 2.8 & 4.7 & 6.3 & 6.3 & 4.6 & 4.5 \\
\hline
\end{tabular}

(c)

\begin{tabular}{|c|c|c|c|c|c|c|c|c|c|c|c|c|c|c|c|c|}
\hline Station & $\begin{array}{c}\text { Length } \\
(\mathrm{km})\end{array}$ & SN11 & HN11 & $\begin{array}{l}\text { EN1 } \\
\text { rth (n }\end{array}$ & HS11 & EV11 & SN11 & HN11 & East (mm) & HS11 & EV11 & SN11 & HN11 & $\begin{array}{l}\text { EN1 } \\
\mathrm{p}(\mathrm{mr}\end{array}$ & HS11 & EV11 \\
\hline TUOR & 110 & 1.1 & 1.2 & 1.2 & 1.3 & 1.1 & 1.7 & 1.6 & 1.6 & 2.0 & 1.7 & 3.6 & 3.6 & 3.7 & 4.2 & 3.6 \\
\hline VIRO & 178 & 1.0 & 1.2 & 1.2 & 1.2 & 1.1 & 1.8 & 2.0 & 2.0 & 2.0 & 1.9 & 3.8 & 4.1 & 4.1 & 4.4 & 3.9 \\
\hline OLKI & 196 & 1.3 & 1.3 & 1.3 & 1.5 & 1.3 & 2.0 & 2.1 & 2.1 & 2.2 & 1.9 & 4.0 & 4.6 & 4.6 & 4.5 & 3.9 \\
\hline DEGE & 224 & 1.2 & 1.3 & 1.3 & 1.3 & 1.2 & 2.1 & 2.2 & 2.2 & 2.3 & 2.1 & 3.8 & 5.2 & 5.1 & 4.0 & 3.7 \\
\hline KIVE & 300 & 1.4 & 1.6 & 1.6 & 1.9 & 1.3 & 1.4 & 1.5 & 1.5 & 1.7 & 1.5 & 3.2 & 3.5 & 3.5 & 3.4 & 3.5 \\
\hline VAAS & 336 & 1.4 & 1.5 & 1.5 & 1.7 & 1.5 & 1.8 & 2.0 & 1.9 & 2.1 & 1.8 & 4.2 & 4.4 & 4.4 & 4.5 & 4.3 \\
\hline JOEN & 390 & 1.4 & 2.0 & 2.0 & 1.7 & 1.5 & 1.9 & 2.2 & 2.2 & 2.3 & 2.0 & 3.9 & 5.6 & 5.6 & 4.7 & 4.2 \\
\hline ROMU & 530 & 1.8 & 2.5 & 2.5 & 2.1 & 2.0 & 1.8 & 2.0 & 2.0 & 2.5 & 1.8 & 5.5 & 6.4 & 6.5 & 6.0 & 5.6 \\
\hline OULU & 548 & 1.6 & 2.4 & 2.4 & 1.9 & 1.8 & 1.6 & 1.9 & 1.9 & 2.0 & 1.7 & 4.0 & 5.4 & 5.4 & 4.4 & 4.2 \\
\hline KUUS & 676 & 1.7 & 2.8 & 2.8 & 1.9 & 1.8 & 1.8 & 2.1 & 2.1 & 2.4 & 2.1 & 4.1 & 5.6 & 5.6 & 4.7 & 4.3 \\
\hline SODA & 808 & 2.3 & 3.6 & 3.6 & 2.7 & 2.6 & 2.0 & 2.3 & 2.3 & 2.4 & 2.1 & 5.4 & 7.4 & 7.4 & 6.1 & 5.5 \\
\hline KEVO & 1069 & 2.6 & 3.8 & 3.8 & 3.1 & 2.8 & 2.3 & 2.8 & 2.8 & 3.0 & 2.5 & 5.7 & 7.4 & 7.4 & 6.4 & 5.8 \\
\hline Mean & & 1.6 & 2.1 & 2.1 & 1.9 & 1.7 & 1.9 & 2.1 & 2.1 & 2.2 & 1.9 & 4.3 & 5.3 & 5.3 & 4.8 & 4.4 \\
\hline
\end{tabular}

tion or increase has been computed with respect to the SNsolution for all the components. Reductions in standard deviation have been denoted with a negative sign (scatter decreases), and increases in standard deviation are marked with a plus sign (scatter increases). Comparing SN with itself yields $0.0 \%$.

In the 00-solutions the decrease in the standard devi- ation with alternative processing schemes is statistically significant, up to $70 \%, 51 \%$ and $65 \%$ in the north, east and up components, respectively. The HS solution gives the highest reductions, as expected, because it is the only scheme that accounts for the azimuthal differences in the 00-solutions. There is no great difference between HNOO and ENOO in the horizontal components, but HNOO per- 
Table 3. Comparison of different processing techniques for all the stations. Numbers show the reduction (negative values) or increase (positive values) in standard deviation in millimetres $(\mathrm{mm})$ and in percentages $(\%)$, compared with the SN-solution.

\begin{tabular}{|c|c|c|c|c|c|c|c|c|c|c|c|c|c|c|c|c|c|c|}
\hline & $\begin{array}{c}\text { SN00 } \\
\text { North } \\
\text { mm }\end{array}$ & $\%$ & $\begin{array}{l}\text { East } \\
\mathrm{mm}\end{array}$ & $\%$ & $\begin{array}{l}\mathrm{Up} \\
\mathrm{mm}\end{array}$ & $\%$ & $\begin{array}{c}\text { SN10 } \\
\text { North } \\
\text { mm }\end{array}$ & $\%$ & $\begin{array}{l}\text { East } \\
\mathrm{mm}\end{array}$ & $\%$ & $\begin{array}{l}\mathrm{Up} \\
\mathrm{mm}\end{array}$ & $\%$ & $\begin{array}{c}\text { SN11 } \\
\text { North } \\
\text { mm }\end{array}$ & $\%$ & $\begin{array}{l}\text { East } \\
\mathrm{mm}\end{array}$ & $\%$ & $\begin{array}{l}\mathrm{Up} \\
\mathrm{mm}\end{array}$ & $\%$ \\
\hline HNxx & -7.0 & -66.4 & -3.6 & -46.7 & -41.3 & -64.1 & 0.9 & 44.0 & 0.1 & 3.9 & 1.6 & 34.9 & 0.5 & 34.0 & 0.2 & 11.5 & 1.0 & 23.5 \\
\hline Enxx & -7.0 & -66.9 & -3.5 & -45.8 & -36.6 & -56.7 & 0.8 & 40.9 & 0.1 & 4.1 & 1.6 & 34.8 & 0.5 & 33.9 & 0.2 & 11.4 & 1.0 & 23.5 \\
\hline HSxx & -7.3 & -69.8 & -3.9 & -50.5 & -41.8 & -64.8 & 0.1 & 3.2 & -0.2 & -6.1 & -0.1 & -1.8 & 0.3 & 18.3 & 0.4 & 21.4 & 0.5 & 12.0 \\
\hline Evxx & -7.0 & -66.2 & -3.5 & -45.8 & -37.1 & -57.5 & 0.1 & 6.4 & 0.1 & 2.4 & -0.2 & -4.6 & 0.1 & 7.5 & 0.1 & 4.4 & 0.1 & 2.5 \\
\hline
\end{tabular}

forms better in the up component, most likely due to the higher resolution of HIRLAM. The EV00 solution yields basically the same reductions as ENO0, indicating that there is no great difference between the NMF and VMF1 in this resolution. Looking at $\mathrm{HNOO}$ and $\mathrm{HSOO}$ reductions, it can be concluded that the better zenith delay model has the greatest effect. However, the slant delay approach provides the highest precision.

For the 10-schemes, the SN10 seems to be the best option. None of the other schemes yield statistically significant improvements. The next-best solution is the HS10, which does not make the solution much better or worse. The HN10 and EN10, which were calculated using the a priori hydrostatic zenith delays, degrade all the components.

In the third case, in which both site-specific parameters and horizontal gradients are estimated, the SN11 is the most reliable solution. The next best solution is the EV11, which can be explained by the gradients in the HS slant delays, as discussed above.

\section{Discussion}

The simulation of non-scientific software shows that using more precise troposphere models reduces the standard deviation of all the components in the GPS time series. In cases where no additional parameters are estimated, the reduction can be up to $60 \%$ compared with the standard solution. The reduction also depends on the length of the vector. There are no great differences between different processing schemes when site-specific parameters and/or gradients are estimated. Standard deviations show a statistically significant reduction only at some stations and components.

The discrepancies we see can be partly due to loading effects that influence all of the GPS stations. The time series, therefore, contain not only observational noise, but also the geophysical loading effects of the atmosphere, hydrology and non-tidal variations of the sea. When troposphere parameters (zenith delays and gradients) and station height are estimated in one adjustment, the parameters are correlated, indicating that a part of the real variation by loading can be compensated by the troposphere parameter estimation, as was discussed in Analysis section. This means that a smaller repeatability (i.e. standard deviation) of station height does not necessarily mean that the tropospheric refraction is handled in a better way. This might be one of the reasons why SN10 and SN11 give such good results.

Other studies have shown improvements when more sophisticated mapping functions are used. However, these studies differ from the present study in terms of processing windows, strategies, baseline lengths, etc. We are also using a regional network, where the troposphere is quite similar for all the stations. In their study, Tesmer et al. (2007) found an improvement of 3, 3.5 and 7\% for the north, east and up components, respectively, when they switched from the NMF to the VMF1 in their VLBI analysis. We see no such distinctive reductions in our results, but our network is not global. Bock et al. (2002) declared a repeatability of 5$10 \mathrm{~mm}$ with a $1-\mathrm{h}$ processing window for the vertical component. Mapping function studies indicate a $50 \%$ reduction in scatter when more sophisticated mapping functions are used (MacMillan and Ma, 1998; Niell, 2001), which is the same order of magnitude we found for our non-site-specific parameter case (00).

We used the GPS in double difference mode, where the coordinates of the other end of the vector are kept fixed. The troposphere is estimated for both ends of the vector. However, it is not known how a possible error in troposphere estimation will affect the final coordinates. The effect of the troposphere could be seen more clearly in PPP (Precise Point Positioning) solutions. A recent study using slant delays and PPP-processing shows improved repeatabilities when ray-traced data are used together with residual troposphere estimation, as compared with standard processing (Hobiger et al., 2008). The improvement achieved by the residual troposphere estimation in their study is in the same order of magnitude as that observed when we compared the HSO0 and HS10 results here, yielding a couple of millimetres in standard deviation for horizontal components and $15-20 \mathrm{~mm}$ for the vertical.

\section{Conclusions}

We have considered the effect of different troposphere estimation techniques on GPS processing, using Bernese v. 5.0 and employing 6 months of data for 13 permanent GPS stations. Five different troposphere model and mapping function combinations were used for the purposes of comparison: the mapping functions NMF and VMF1, the raytracing-based slant delay model, and, finally, two NWMderived troposphere zenith delays used with the Niell mapping function.

The ray-tracing-based troposphere slant delays were implemented in GPS processing through RINEX file manipulation at the observation level. The advantage of this method is that it is independent of processing software and is also applicable to other error sources, such as ionosphere delay or loading.

We have shown that when no additional parameters are 
estimated, the standard deviation of the GPS time series is reduced by $60 \%$ in all three components when NWMbased tropospheric delays are introduced. In this case, the slant delays derived by ray tracing yielded the best results. The improved troposphere handling also reduces the baseline length dependence of the standard deviation. However, the results do show further improvements when site-specific troposphere parameters and gradients are estimated, indicating that the numerical weather models are not at an accuracy level that makes site-specific residual troposphere estimation unnecessary.

When site-specific parameters or both site-specific parameters and horizontal gradients are estimated, there are no statistically significant differences in the different processing schemes. The standard Bernese processing yields the lowest standard deviations. The results show that an a priori reduction of observations by modelled slant troposphere delays gives comparable results to the estimation of troposphere zenith delay and is therefore an appropriate method. Estimating the site-specific troposphere parameters and horizontal gradients is still mandatory when the highest accuracy in double difference GPS processing is required.

Acknowledgments. This work was partly funded by the Finnish Funding Agency for Technology and Innovation (TEKES), decision number 40415/04 and by the Finnish Academy of Science, decision number 117094.

\section{References}

Bock, O., J. Tarniewicz, Ch. Thom, and J. Pelon, The effect of inhomogeneities in the lower atmosphere on coordinates determined from GPS measurements, Phys. Chem. Earth, 27, 323-328, 2002.

Boehm, J. and H. Schuh, Vienna mapping functions in VLBI analyses, Geophys. Res. Lett., 31, L01603, doi:10.1029/2003GL018984, 2004.

Boehm, J., B. Werl, and H. Schuh, Troposphere mapping functions for GPS and very long baseline interferometry from European Centre for Medium-Range Weather Forecasts operational analysis data, J. Geophys. Res., 111, B02406, doi:10.1029/2005JB003629, 2006 a.

Boehm, J., A. Niell, P. Tregoning, and H. Schuh, Global Mapping Function (GMF): A new empirical mapping function based on numerical weather model data, Geophys. Res. Lett., 33, L07304, doi:10. 1029/2005GL025546, 2006b.

Boucher, C., Z. Altamimi, P. Sillard, and M. Feissel-Vernier, The ITRF2000 (IERS Technical Note; 31) Frankfurt am Main: Verlag des Bundesamts für Kartographie und Geodäsie, 289 pp., 2004.

Brandt, S., Data analysis, Statistical and computational methods for scientists and engineers, Springer-Verlag, 1999.

Dach, R., U. Hugentobler, P. Fridez, and M. Meindl (Eds.), Bernese GPS Software, Version 5.0, 612 pp., Astronomical Institute, University of Berne, 2007.

Elgered, G., H.-P. Plag, H. van der Marel, S. Barlag, and J. Nash (Eds.), COST Action 716 - Exploitation of ground-based GPS for operational numerical weather prediction and climate applications, European Union, Rep. EUR 21639, COST Office, Brussels, Belgium, 234 pp., 2005.

Eresmaa, R. and H. Järvinen, An observation operator for ground-based GPS slant delays, Tellus, 58A, 131-140, 2006.

Eresmaa, R., H. Järvinen, M. Nordman, M. Poutanen, J. Syrjärinne, and J.P. Luntama, Parameterization of tropospheric delay correction for mobile GNSS positioning: a case study of a cold front passage, Meteorol.
Applic., 2008 (submitted).

Hobiger, T., R. Ichikawa, T. Takasu, Y. Koyama, and T. Kondo, Ray-traced troposphere slant delays for precise point positioning, Earth Planets Space, 60, e1-e4, 2008.

Krügel, M., D. Thaller, V. Tesmer, M. Rothacher, D. Angermann, and R. Schmid, Tropospheric parameters: combination studies based on homogeneous VLBI and GPS data, J. Geod., 81, 515-527, doi:10. 1007/s00190-006-0127-8, 2007.

MacMillan, D. S. and C. Ma, Using meteorological data assimilation models in computing tropospheric delays at microwave frequencies, Phys. Chem. Earth, 23, 97-102, 1998.

Niell, A. E., Global mapping functions for the atmosphere delay at radio wavelengths, J. Geophys. Res., 101(B2), 3227-3246, 1996.

Niell, A. E., Preliminary evaluation of atmospheric mapping functions based on numerical weather models, Phys. Chem. Earth, 26, 475-480, 2001.

Niell, A. E., A. J. Coster, F. S. Solheim, V. B. Mendes, P. C. Toor, R. B. Langley, and C. A. Upham, Comparison of measurements of atmospheric wet delay by radiosonde, water vapor radiometer, GPS, and VLBI, J. Atmos. Oceanic Technol., 18, 830-850, 2001.

Nordman, M., R. Eresmaa, M. Poutanen, H. Järvinen, H. Koivula, and J.P. Luntama, Using numerical weather prediction model derived tropospheric slant delays in GPS processing: a case study, Geophys., 43(1-2), 43-51, 2007.

Poutanen, M., J. Jokela, M. Ollikainen, H. Koivula, M. Bilker, and H. Virtanen, Scale variation of GPS time series, in A Window on the Future of Geodesy, IAG General Assembly in Sapporo, Japan 2003, edited by F. Sansò, 15-20, IAG Symposia 128, Springer-Verlag, 2005.

Saastamoinen, J., Contributions to the theory of atmospheric refraction, Bull. Géodésique, 107, 13-34, 1973.

Simmons, A. J. and J. K. Gibson (Eds.), The ERA-40 Project Plan, ERA40 Proj. Rep. Ser. 1, Eur. Cent. for Medium-Range Weather Forecasts, Reading, U.K., 2000.

Snajdrova, K., J. Boehm, P. Willis, R. Haas, and H. Schuh, Multitechnique comparison of tropospheric zenith delays derived during the CONT02 campaign, J. Geod., 79, 613-623, doi:10.1007/s00190-0050010-z, 2006.

Stoyanov, B., R. Haas, and L. Gradinarsky, Calculating mapping functions from the HIRLAM numerical weather prediction model, in International VLBI Service for Geodesy and Astrometry 2004 General Meeting Proceedings, edited by N. R. Vandenberg and K. D. Baver, 471-475, NASA/CP-2004-212255, 2004.

Tesmer, V., J. Boehm, R. Heinkelmann, and H. Schuh, Effect of different tropospheric mapping functions on the TRF, CRF and position timeseries estimated from VLBI, J. Geod., doi:10.1007/s00190-006-0126-9, 2007.

Tregoning, P. and T. van Dam, Atmospheric pressure loading corrections applied to GPS data at the observation level, Geophys. Res. Lett., 32, L22310, doi:10.1029/2005GL024104, 2005.

Troller, M., A. Geiger, E. Brockmann, and H.-G. Kahle, Determination of the spatial and temporal variation of tropospheric water vapour using CGPS networks, Geophys. J. Int., 167, 509-520, doi:10.1111/j.1365246X.2006.03101.x, 2006.

Undén, P., L. Rontu, H. Järvinen, P. Lynch, J. Calvo, G. Cats, J. Cuxart, K. Eerola, C. Fortelius, J. A. Garcia-Moya, C. Jones, G. Lenderlink, A. McDonald, R. McGrath, B. Navascués, N. Woetman Nielsen, V. Ødegaard, E. Rodriguez, M. Rummukainen, R. Rõõm, K. Sattler, B. Hansen Sass, H. Savijärvi, B. Wichers Schreur, R. Sigg, H. The, and A. Tijm, HIRLAM-5 Scientific Documentation, Available from Hirlam-5 Project, c/o Per Undén, SMHI, S-60176, Norrköping, Sweden, 144 pp., 2002.

M. Nordman (e-mail: maaria.nordman@fgi.fi), R. Eresmaa, J. Boehm, M. Poutanen, H. Koivula, and H. Järvinen 